\title{
TINGKAT RISIKO PEKERJA PADA MESIN PIERCING TUBE DENGAN MENGGUNAKAN METODE RAPID ENTIRE BODY ASSESSMENT (REBA) DAN RAPID UPPER LIMB ASSESSMENT (RULA) DI DEPARTEMEN PRESS SHOP PT. $X$.
}

\author{
Popy Yuliarty ${ }^{1)}$, Andri Wibowo' \\ 1,2) Prodi Teknik Industri, Universitas Mercu Buana \\ popy.yuliarty@mercubuana.ac.id
}

\begin{abstract}
Abstrak. Kenyamanan dan keamanan di tempat kerja harus diwujudkan karena karyawan sangat rentan mengalami kecelakan ketika bekerja. Hal ini tentu membuat adanya banyak kerugian seperti biaya, waktu, efisisensi dan efektivitas kerja serta berakibat pada produktivitas kerja yang menurun. Banyak hal yang harus diperhatikan di dalam line produksi agar line produksi bisa di jadikan tempat yang aman dan nyaman. Rumusan masalah dalam penelitian ini adalah berapa tingkat risiko ergonomi terhadap proses produksi pada karyawan di departemen (Press Shop) PT. X. Tujuan dari penelitian ini adalah rekomendasi perbaikan yang tepat untuk mengurangi / menyelesaikan permasalahan karyawan terhadap keletihan pada karyawan didepartemen Press Shop di PT. X. Metode yang digunakan pada penelitian ini adalah REBA, RULA serta kuisioner NBM. Untuk menghitung nilai skor RULA dan REBA peneliti menggunakan software RULA REBA Assessment pada tiap pengamatan aktifitas produksi. Hasil dari penelitian ini adalah untuk 3 skor tertinggi keluhan yang dirasakan operator yaitu sakit pinggang (7), sakit pada lengan atas bagian kanan total skor (6), sakit pada bagian punggung total skor (5). Untuk Skor REBA pada pierching tube header pipe adalah 8, termasuk dalam resiko tinggi sehingga perlu adanya perbaikan, Skor RULA pada pierching tube header pipe 7, memiliki level risiko tinggi perlu adanya perbaikan. Solusi perbaikan dari hasil data penelitian yaitu perbaikan terhadap edukasi terhadap operator, perbaikan pada posisi layout kerja dan membuat modifikasi meja pada mesin.
\end{abstract}

Kata kunci : RULA, REBA, NBM, Risiko Pekerja, Ergonomi

\section{PENDAHULUAN}

PT X Tbk, adalah salah satu perusahaan automotive Indonesia. Perusahaan ini menghasilkan sebuah produksi yaitu berbagai jenis radiator yang di pasarkan ke dalam negeri dan luar negeri. Departemen Press Shop yang memproduksi header pipe menghadapi perampingan guna menekan biaya produksi pada proses produksinya, berawal dari efisiensi cost yang dilakukan dimana pada awalnya proses produksi menggunakan 1 manpower untuk 1 mesin kini di efisiensikan menjadi setiap 1 manpower mengoperasikan 2 mesin secara bersamaan tentu saja hal tersebut membutuhkan tenaga ekstra dan meningkatkan resiko kelelahan bagi setiap operator dalam kondisi kerjanya.

Dalam satu hari kerja (kurang lebih 8 jam), karyawan hampir $90 \%$ menghabiskan waktu kerjanya dalam posisi berdiri berhadapan dengan mesin. Jika posisi aktivitas bekerja yang digunakan karyawan dalam bekerja tidak dirancang dengan baik, akan mengakibatkan kurang nyamannya karyawan bekerja, ketegangan otot, dan rasa letih selama waktu kerja. Setiap pekerjaan pasti akan menghasilkan sebuah kelelahan kerja yaitu kelelahan fisik yang dialami oleh karyawan tersebut. Dengan kewaspadaan yang baik, halhal negatif yang akan terjadi dapat diantisipasi terhadap berbagai risiko yang mempengaruhi kehidupan para pekerja. Berbagai risiko tersebut adalah kemungkinan terjadinya penyakit akibat kerja, penyakit yang berhubungan dengan pekerjaan dan kecelakaan akibat kerja yang dapat menyebabkan kecacatan atau kematian ( Tommy : 2013). Antisipasi ini harus dilakukan oleh semua pihak dengan cara penyesuaian antara pekerja, proses kerja dan lingkungan kerja.

Melalui pendekatan ergonomi yaitu Sasaran pengamatan ergonomi ialah manusia pada saat bekerja dalam lingkungan dengan menggunakan Metode Rapid Entire Body 
Assessment (REBA) Dan Rapid Upper Limb Assessment (RULA) diharapkan dapat menyesuaikan ukuran tempat kerja dengan dimensi tubuh agar tidak melelahkan bertujuan agar sesuai dengan kebutuhan tubuh pekerja (E.Nurmianto : 2008). Rumusan masalah dalam penelitian ini adalah untuk mengetahui berapa tingkat risiko ergonomi terhadap proses produksi pada karyawan di departemen (Press Shop) PT. X dan apakah rekomendasi perbaikan yang tepat untuk mengurangi/ menyelesaikan permasalahan karyawan terhadap keletihan pada karyawan didepartemen Press Shop di PT. X.

\section{METODE PENELITIAN}

Penelitian ini menggunakan model kuantitatif dan model kualitatif atau dengan kata lain model campuran. Flowchart penelitian ini dapat dilihat pada gambar 1 berikut ini :

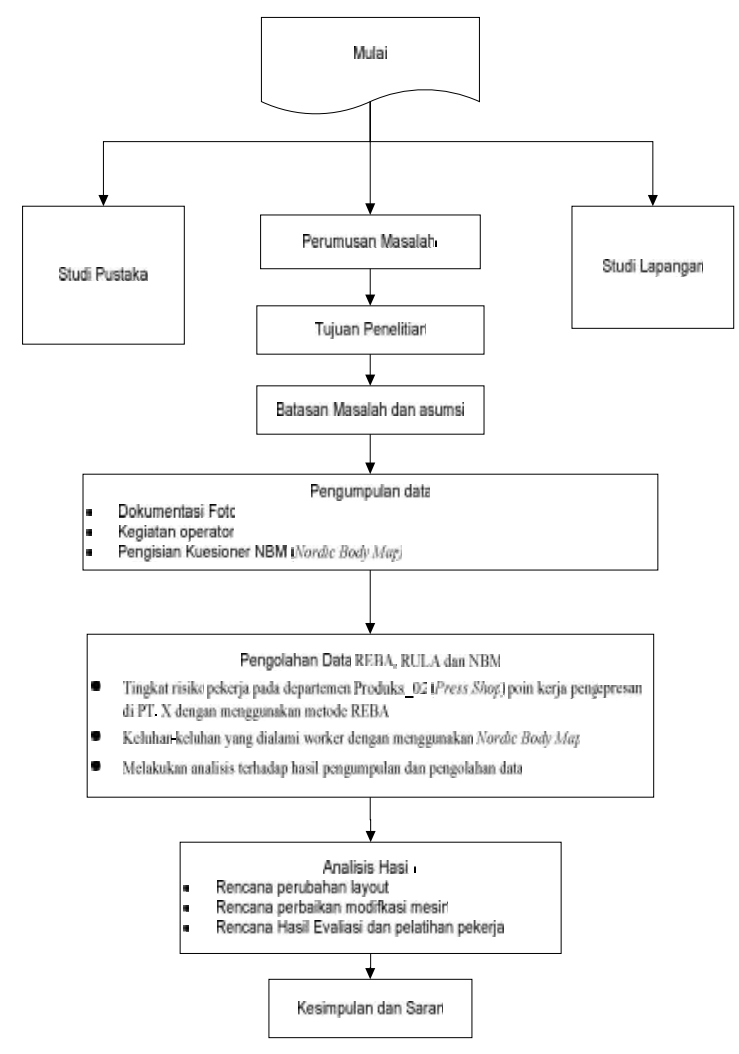

Gambar 1. Flowchart penelitian

Tahapan pada penelitian ini diawali dengan observasi langsung ke Dept Press Shop untuk mengidentifikasi masalah yang terjadi. Kemudian memilih metode penyelesaian masalah yang tepat yaitu metode RULA dan REBA. Pengumpulan data dilakukan dengan mendokumentasikan seluruh aktifitas pekerjaan operator dan penyebaran luisioner Nordic Body Map, kemudian melakukan analisis berdasar metode yang telah dipilih dan menarik kesimpulan atas dasar analisis yang telah dilakukan dalam penelitian ini.

\section{HASIL DAN PEMBAHASAN}

Tahap awal yaitu penyebaran kuisioner Nordic Body Map kepada 4 orang operator. Hasil rekap kuisioner NBM dapat dilihat pada Grafik 1 . 


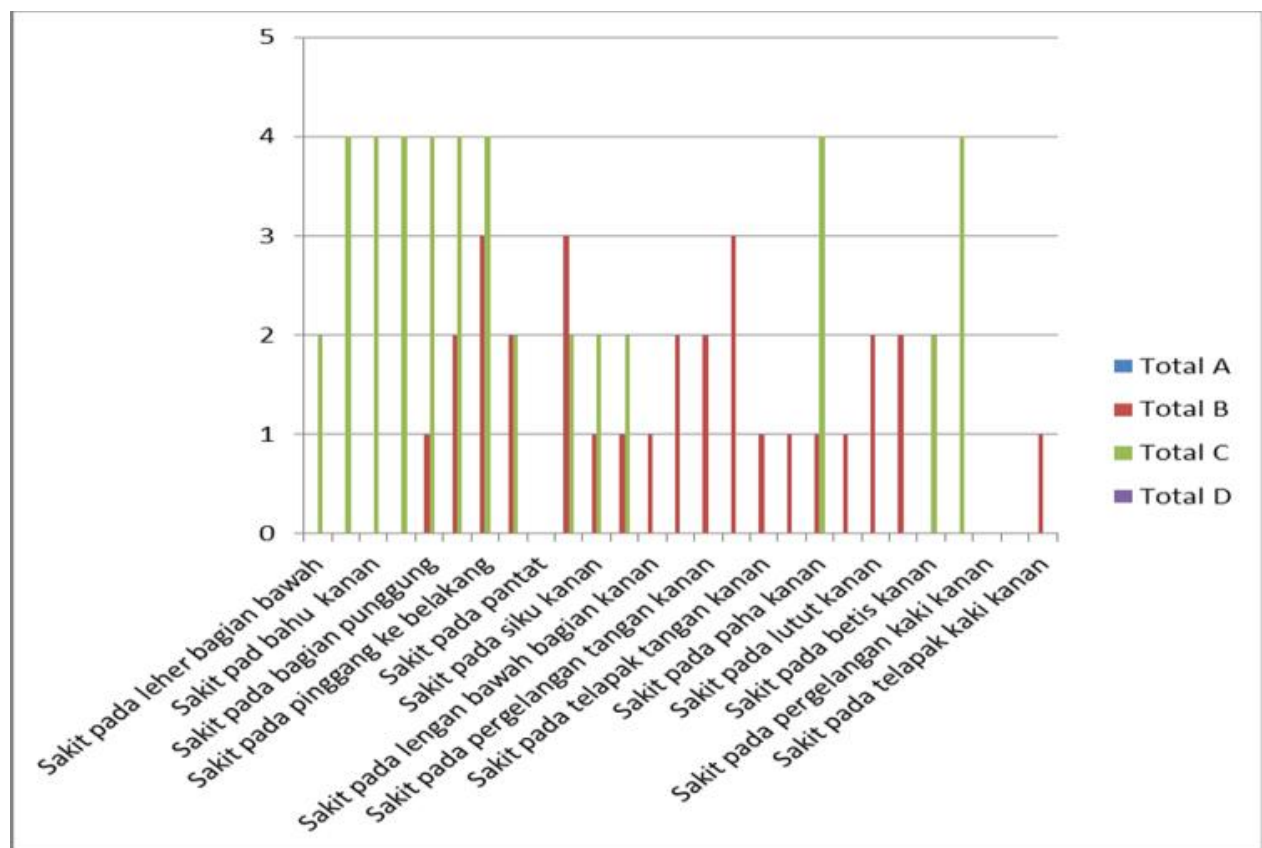

Grafik 1. Diagram Hasil Kuesioner

Berdasarkan diagram diatas, dapat dilihat bahwa :

1. Bagian tubuh yang paling banyak mengalami sakit adalah pada bahu bagian kiri, bahu kanan, lengan atas bagian kiri, punggung, lengan atas bagian kanan, pinggang kebelakang, sakit pada pergelangan kaki kiri dengan skor 3 nilai C (Sakit) .

2. Setelah itu pada pinggang kebelakang, Sakit pada siku kiri, Sakit pada telapak tangan kirin dengan skor 2 nilai B (sedikit Sakit).

3. Setelah itu berdasarkan tabel rangking peringkat no.1 pada pinggang kebelakang dengan skor 2 nilai B (Sedikit Sakit) dan skor 3 nilai C (Sakit).
4. Adapun rangking selanjutnya pada tabel rangking peringkat no.2 sakit pada lengan atas bagian kanan dengan skor 2 nilai B (Sedikit Sakit) dan skor 3 nilai C (Sakit).

Hal ini dapat terjadi dikarenakan pekerja bekerja dengan posisi memutar tubuh bagian pinggang setiap harinya dan menggunakan tubuh bagian kanan dan kiri (siku tangan kanan dan kiri, bahu kanan dan kiri) dalam melakukan pekerjaan mereka. Berikut adalah Tabel hasil pengamatan Reba yang dibagi menjadi 2 grup yaitu A dan B. Dibawah ini adalah Tabel grup A yang mengamati tubuh bagian leher, punggung dan kaki dapat dilihat pada Tabel 1.

Tabel 1. Pengamatan Grup A Reba Lubang Tube Piercing

\begin{tabular}{|c|c|c|c|c|}
\hline No & Gambar Posisi & Kegiatan & Hasil Pengamatan & Skor \\
\hline $\begin{array}{c}\text { Posisi } \\
\text { Leher }\end{array}$ & & $\begin{array}{c}\text { Meletakan } \\
\text { part pada } \\
\text { mesin lubang } \\
\text { tube } \\
\text { Piercing }\end{array}$ & $\begin{array}{c}\text { Posisi leher pekerja } \\
\text { mengalami ekstensi dengan } \\
\text { sudut 22 }\end{array}$ & 2 \\
& & & & 2 \\
\hline
\end{tabular}




\begin{tabular}{|c|c|c|c|}
\hline $\begin{array}{c}2 . \\
\text { Posisi } \\
\text { Punggung }\end{array}$ & $\begin{array}{c}\text { Meletakan } \\
\text { part pada } \\
\text { mesin lubang } \\
\text { tube } \\
\text { Piercing }\end{array}$ & $\begin{array}{l}\text { Posisi Punggung pekerja } \\
\text { mengalami fleksi dengan } \\
\text { sudut } 43^{\circ}\end{array}$ & 3 \\
\hline $\begin{array}{c}3 . \\
\text { Posisi } \\
\text { Kaki }\end{array}$ & $\begin{array}{l}\text { Meletakan } \\
\text { part pada } \\
\text { mesin lubang } \\
\text { tube } \\
\text { Piercing }\end{array}$ & $\begin{array}{l}\text { Posisi kaki pekerja } \\
\text { menapakkan kaki kanan } \\
\text { menekuk } 20^{\circ} \text { pada saat } \\
\text { menginjak pedal }\end{array}$ & 2 \\
\hline
\end{tabular}

Tabel Grup B yang mengelompokan pengamatan pada bagian tubuh lengan atas, lengan bawah dan pergelangan tangan dapat dilihat pada tabel 2 .

Tabel 2. Pengamatan Grup B Reba

\begin{tabular}{|c|c|l|l|l|}
\hline $\begin{array}{c}\text { No } \\
\text { Lengan } \\
\text { Atas }\end{array}$ & Gambar Posisi & Kegiatan & $\begin{array}{l}\text { Hasil } \\
\text { Pengamatan }\end{array}$ & Skor \\
\hline $\begin{array}{c}\text { Lengan } \\
\text { Bawah }\end{array}$ & $\begin{array}{l}\text { Lengan atas pada } \\
\text { saat membawa } \\
\text { part dan } \\
\text { melekatan ke } \\
\text { mesin lubang tube } \\
\text { piercing }\end{array}$ & $\begin{array}{l}\text { Posisi } \\
\text { lengan } \\
\text { membentuk } \\
\text { sudut } 65^{\circ}\end{array}$ & 3 \\
\hline $\begin{array}{c}\text { Pergelangan } \\
\text { tangan }\end{array}$ & & $\begin{array}{l}\text { Lengan bawah } \\
\text { pada saat } \\
\text { membawa part } \\
\text { dan melekatan ke } \\
\text { mesin lubang tube } \\
\text { piercing }\end{array}$ & $\begin{array}{l}\text { Lengan } \\
\text { bawah } \\
\text { menghadap } \\
\text { posisi } 90^{\circ} \\
\text { Sejajar }\end{array}$ & 2 \\
\hline $\begin{array}{l}\text { Pergelangan } \\
\text { tangan pada saat } \\
\text { meletakan part } \\
\text { pada mesin lubang } \\
\text { tube piercing }\end{array}$ & $\begin{array}{l}\text { Pergelangan } \\
\text { tangan } \\
\text { terjadi } \\
\text { refleksi 20 }\end{array}$ & 2 \\
\hline
\end{tabular}


Dari hasil pengamatan Tabel grup A dan B maka peneliti melakukan perhitungan kontraksi - kontraksi yang terjadi pada grup A dan B yaitu dengan membuat diagram REBA Assessment Worksheet. Dapat di lihat pada gambar 2 berikut ini :

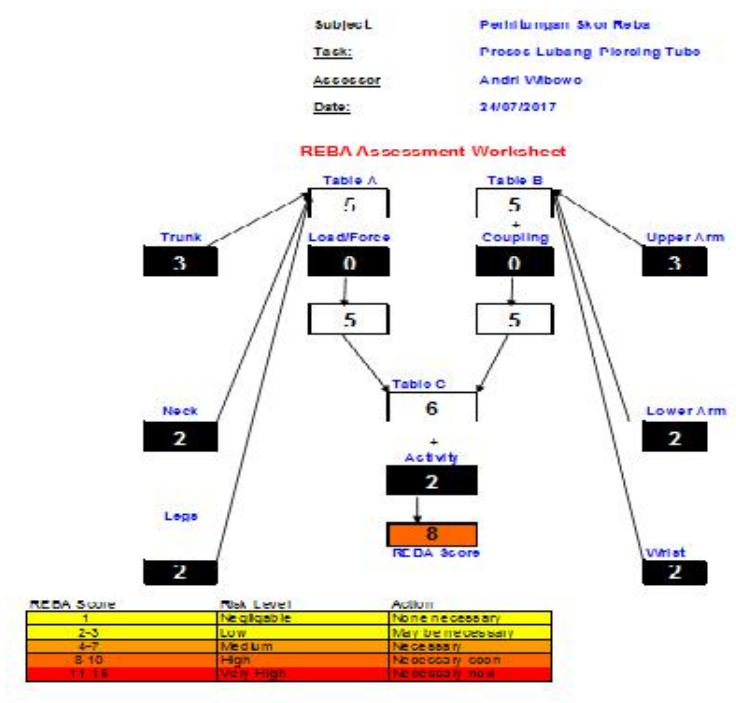

Gambar 2 Diagram REBA Assessment Worksheet Proses Tube piercing

Piercing tube header pipe memiliki skor REBA akhir 8 yaitu tingkat risiko tinggi, sehingga harus dilakukan perbaikan dan saat itu juga untuk meminimalisir paparan ergonomi pada pekerja.
Berikut adalah Tabel hasil pengamatan Rula yang dibagi menjadi 2 grup yaitu $\mathrm{A}$ dan $\mathrm{B}$. Tabel grup A yang mengamati tubuh bagian lengan atas, lengan bawah dan pergelangan tangan dapat dilihat pada Tabel 3.

Tabel 3 Pengamatan Grup A Rula Lubang Tube piercing

\begin{tabular}{|c|c|c|c|c|}
\hline No & Gambar Posisi & Kegiatan & Hasil Pengamatan & Skor \\
\hline $\begin{array}{l}1 \text { Posisi } \\
\text { Lengan } \\
\text { Atas }\end{array}$ & & $\begin{array}{l}\text { Meletakan part pada } \\
\text { mesin lubang Tube } \\
\text { Piercing }\end{array}$ & $\begin{array}{l}\text { Posisi lengan membentuk sudut } 65^{\circ} \\
\text { di beri Skor } 3 \text { dan posisi lengan } \\
\text { terangkat di beri Skor } 1 \text {. Sehingga } \\
\text { total skor }=3+1\end{array}$ & 4 \\
\hline $\begin{array}{l}2 \text { Posisi } \\
\text { Lengan } \\
\text { Bawah }\end{array}$ & & $\begin{array}{c}\text { Meletakan part pada } \\
\text { mesin lubang Tube } \\
\text { Piercing }\end{array}$ & $\begin{array}{l}\text { Lengan bawah menghadap posisi } \\
90^{\circ} \text { Sejajar di beri skor } 1 \text { dan posisi } \\
\text { lengan terdapat gerakan terangkat di } \\
\text { beri skor } 1 \text {. Sehinggan diberi total } \\
\text { skor }=2\end{array}$ & 2 \\
\hline $\begin{array}{l}3 \text { Posisi } \\
\text { lengan } \\
\text { bawah }\end{array}$ & & $\begin{array}{c}\text { Meletakan part pada } \\
\text { mesin lubang Tube } \\
\text { Piercing }\end{array}$ & $\begin{array}{l}\text { Pergelangan tangan terjadi refleksi } \\
20^{\circ} \text { di beri skor } 3\end{array}$ & 3 \\
\hline
\end{tabular}


Tabel Grup B yang mengelompokan pengamatan pada bagian tubuh leher,

punggung dapat dilihat pada tabel 4 .

Tabel 4. Pengamatan Grup B Rula Lubang Tube Piercing

\begin{tabular}{|c|c|c|c|c|}
\hline No & Gambar Posisi & Kegiatan & Hasil Pengamatan & Skor \\
\hline $\begin{array}{l}1 . \\
\text { Leher }\end{array}$ & & $\begin{array}{l}\text { Meletakan part } \\
\text { pada mesin } \\
\text { lubang Piercing } \\
\text { Tube Square }\end{array}$ & $\begin{array}{l}\text { Posisi leher pekerja mengalami } \\
\text { ekstensi dengan sudut } 45^{\circ} \text { di beri skor } \\
=3 \text { dan Posisi leher menekuk di beri } \\
\text { skor } 2\end{array}$ & 5 \\
\hline $\begin{array}{c}2 . \\
\text { Punggung }\end{array}$ & & $\begin{array}{l}\text { Meletakan part } \\
\text { pada mesin } \\
\text { lubang Tube } \\
\text { Piercing }\end{array}$ & $\begin{array}{l}\text { Posisi Punggung pekerja mengalami } \\
\text { fleksi dengan sudut } 30^{\circ} \text { di beri skor }= \\
3 \text { dan Posisi punggung membungkuk } \\
\text { di beri skor } 2\end{array}$ & 5 \\
\hline
\end{tabular}

Dari hasil pengamatan Tabel grup A dan B maka peneliti melakukan perhitungan kontraksi - kontraksi yang terjadi pada grup A dan B yaitu dengan membuat diagram Rula Assessment Worksheet. Dapat di lihat pada Gambar 3.

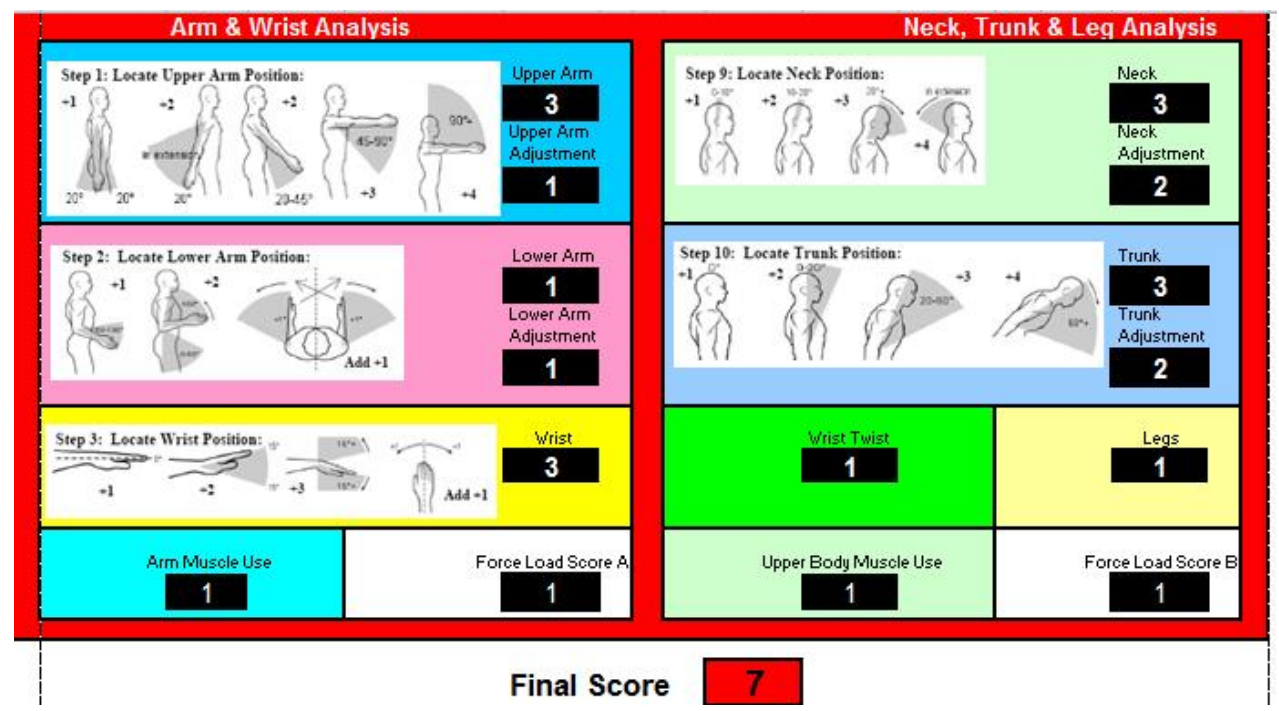

Gambar 3. Diagram RULA Assessment Worksheet Proses Lubang Tube piercing

Piercing tube header pipe memiliki skor RULA akhir 7 yaitu tingkat risiko tinggi, sehingga harus dilakukan perbaikan dan saat itu juga untuk meminimalisir paparan ergonomi pada pekerja.

Selain perbaikan yang dilakukan terhadap manusia, perbaikan yang harus dilakukan adalah untuk memperbaiki design tempat kerja. Berdasarkan hasil kuesioner diketahui bahwa rasa sakit / nyeri otot yang paling sering dialami oleh pekerja adalah dibagian pinggang ke belakang, sehingga harus dilakukan perbaikan pada posisi lay out kerja. Lay out awal dapat dilihat pada gambar 4, dan usulan pada gambar 5. 


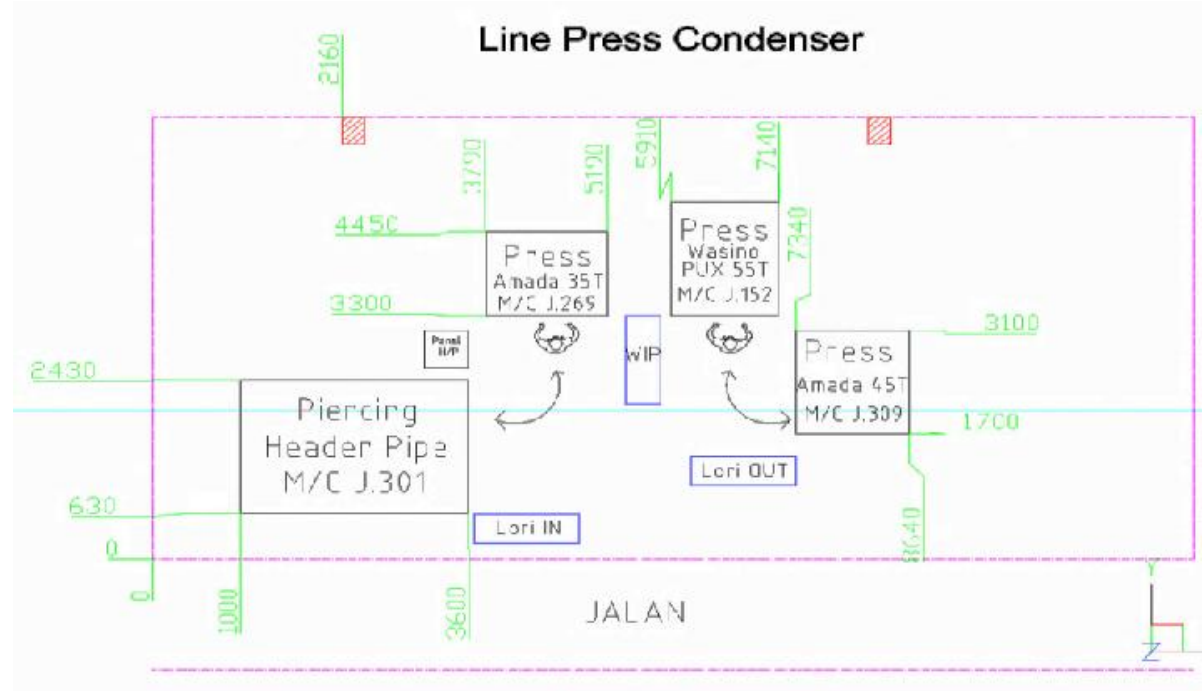

Gambar 4 Design Lay Out awal

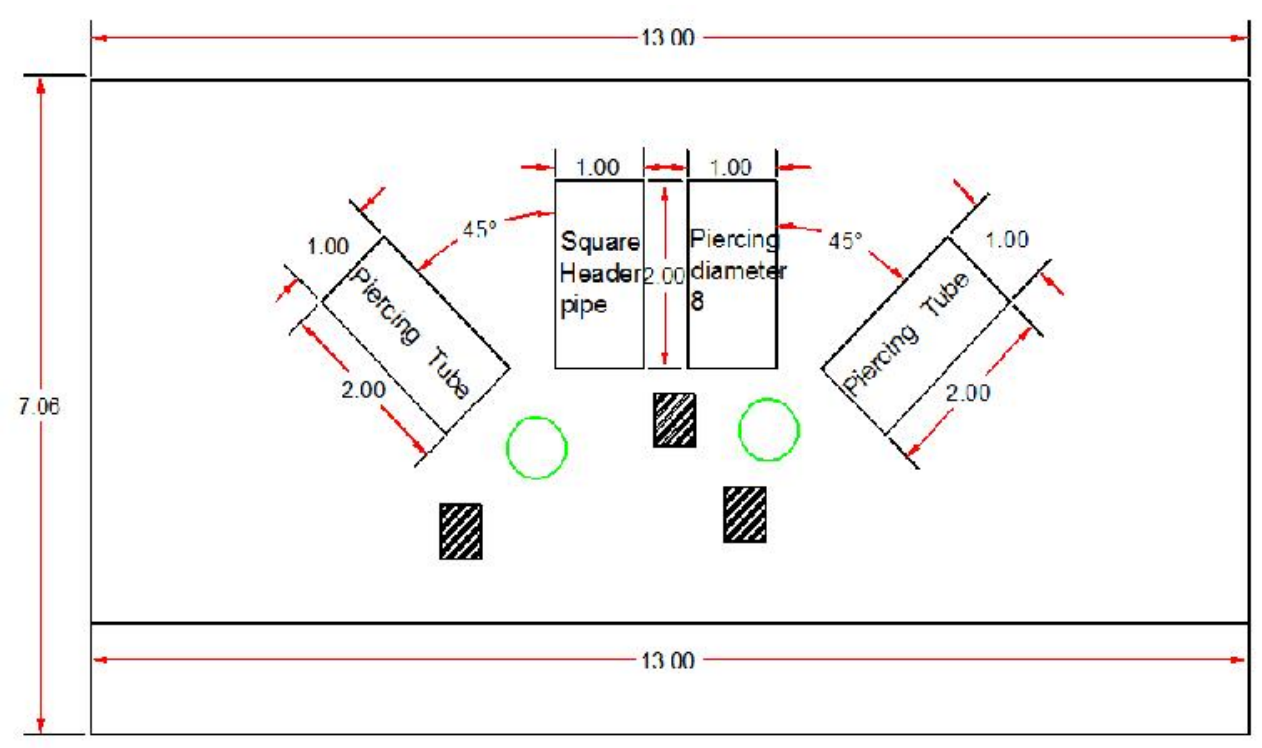

Gambar 4 Design Lay Out Usulan

\section{KESIMPULAN}

Berdasarkan hasil analisis data pada bab sebelumnya, penelitian yang telah dilakukan mendapatkan kesimpulan 3 point sebagai berikut :

1. Dari hasil analisa menggunakan kuesioner Nordik Body Map dapat di ketahui 3 skor tertinggi keluhan pekerja yaitu:

a) Sakit pada pinggang ke belakang total skor 7 b) Sakit pada lengan atas bagian kanan total skor 6

c) Sakit pada bagian punggung total skor 5

Dari berdasarkan kesimpulan point a diatas terindikasi terjadinya keluhan pekerja, sehingga perlu adanya perbaikan berupa redesign tempat kerja dan pembekalan kepada operator berupa pengetahuan tentang proses posisi dalam bekerja 
2. Hasil Analisa menggunakan REBA Rapid Entries Body Assessment) yaitu : Piercing tube header pipe, skor 8 resiko tinggi, perlu adanya perbaikan

3. Hasil Analisa menggunakan RULA ( Rapid Upper Limb Assessment) yaitu : Piercing tube header pipe, skor 7 resiko tinggi, perlu adanya perbaikan

\section{DAFTAR PUSTAKA}

[1]. Ansari, A N, and M J Sheikh. "Evaluation of work Posture by RULA and REBA: A Case Study." IOSR Journal of Mechanical and Civil
Engineering (IOSR-JMCE) ISSN:

2320-334X, Volume 11, Issue 4, 2014: 18-23.

[2]. E, Nurmianto. Ergonomi Konsep Dasar Dan Aplikasinya. Surabaya: Guna Widya, 2008.

[3]. Santoso, G. Ergonomi Manusia, Peralatan dan Lingkungan. Jakarta: Prestasi Pustaka, 2004.

[4]. Sativani, Z. www.ja.scribd.com. 7 13, 2010.

www.ja.scribd.com/doc/130793132/m yalgia-otot. (accessed 82 , 2017).

[5]. Tommy. "Artikel Myalgia." Seputar Media Internal HPME, 2013: 9. 